\title{
Protein or Enzyme Type Measurement
}

National Cancer Institute

\section{Source}

National Cancer Institute. Protein or Enzyme Type Measurement. NCI Thesaurus. Code C64430.

A term that refers to a chemistry test measuring a specific protein or enzyme in the peripheral blood or body fluid. 